\title{
Limitations of widely used high-risk human papillomavirus laboratory-developed testing in cervical cancer screening
}

This article was published in the following Dove Press journal:

Drug, Healthcare and Patient Safety

I November 2012

Number of times this article has been viewed

\author{
Sonya Naryshkin' \\ R Marshall Austin ${ }^{2}$ \\ 'Department of Pathology, Mercy \\ Health System, Janesville, WI; \\ ${ }^{2}$ Department of Pathology, Magee- \\ Womens Hospital of University \\ of Pittsburgh Medical Center, \\ Pittsburgh, PA, USA
}

Objective: To increase awareness of the limitations of high-risk human papillomavirus (hrHPV) laboratory-developed testing (LDT) widely used in US cervical cancer screening.

Methods and results: A young woman in her 30s was diagnosed and treated for stage 1B1 cervical squamous cell carcinoma in which HPV 16 DNA was detected using polymerase chain reaction testing. Both 1 month before and 42 months before cervical cancer diagnosis, the patient had highly abnormal cytology findings; however, residual SurePath ${ }^{\mathrm{TM}}$ (Becton, Dickson and Company, Franklin Lakes, NJ) vial fluid yielded negative Hybrid Capture 2 (HC2; Qiagen NV, Hilden, Germany) hrHPV LDT results from each of the two specimens. This prompted questions to be asked concerning the performance characteristics of hrHPV LDT. A review of the available data indicates that (1) purification of DNA from SurePath specimens requires complex sample preparation due to formaldehyde crosslinking of proteins and nucleic acids, (2) HC2-SurePath hrHPV testing had not been Food and Drug Administration-approved after multiple premarket approval submissions, (3) detectible hrHPV DNA in the SurePath vial decreases over time, and (4) US laboratories performing HC2-SurePath hrHPV LDT testing are not using a standardized manufacturer-endorsed procedure.

Conclusion: Recently updated cervical screening guidelines in the US recommend against the use of hrHPV LDT in cervical screening, including widely used HC2 testing from the SurePath vial. The manufacturer recently issued a technical bulletin specifically warning that use of SurePath samples with the HC2 hrHPV test may provide false negative results and potentially compromise patient safety. Co-collection using a Food and Drug Administration-approved hrHPV test medium is recommended for HPV testing of patients undergoing cervical screening using SurePath samples.

Keywords: HPV, SurePath, Hybrid Capture 2, LDT, cervical screening

\section{Introduction}

Since 2001, adjunctive high-risk human papillomavirus (hrHPV) testing has become increasingly integrated along with cytologic testing as a part of routine US cervical cancer screening, initially as a "preferred" reflex test after atypical cells of undetermined significance liquid-based cytology results and on a more widespread basis after 2003 Food and Drug Administration (FDA) approval for routine cytology and HPV cotesting of women 30 years and older. ${ }^{1,2}$ Recently updated cervical screening guidelines from the American Cancer Society, the American Society for Colposcopy and Cervical Pathology, and the American Society for Clinical Pathology have proposed significantly lengthened screening intervals, particularly for patients with negative hrHPV test results and either negative or equivocally abnormal (atypical cells of undetermined significance)
Correspondence: Sonya Naryshkin Mercy Health System, Department of Pathology, 1000 Mineral Point Ave, PO Box 5003, Janesville,

WI 53547-5003, USA

$\mathrm{Tel}+\mathrm{I} 6087566827$

Fax + I 6087566828

Emailsnaryshkin@mhsjvl.org 
cytology findings. ${ }^{3}$ For women 30 years and older with either hrHPV-negative atypical cells of undetermined significance or "double negative" results, a screening interval of 5 years has for the first time been recommended. ${ }^{3}$ The guidelines, however, emphasize that the new extended screening intervals following negative hrHPV test results are based on HPV tests with performance characteristics similar to HPV tests used in the supporting evidence. ${ }^{3}$ Since at least one-third of all US hrHPV tests use laboratory-developed test (LDT) methodology, largely exempt from regulatory oversight by the FDA and unlikely to have undergone rigorous evaluation using grade $3+$ or grade $2+$ cervical intraepithelial neoplasia clinical endpoints in properly designed trials, ${ }^{3,4}$ the guidelines publications specifically recommend against the use of HPV LDTs for cervical cancer screening. ${ }^{3}$

The most common form of hrHPV LDT to date has been Hybrid Capture 2 (HC2; Qiagen NV, Hilden, Germany) performed on residual SurePath ${ }^{\mathrm{TM}}$ vial fluid (Becton, Dickinson and Company, Franklin Lakes, NJ). ${ }^{5-7}$ Although HC2 hrHPV testing is FDA-approved from both the Digene ${ }^{\circledR}$ (Qiagen) specimen transport medium tube (Qiagen) and the methanol-based PreservCyt ${ }^{\mathbb{B}}$ vial (Hologic, Inc, Bedford, MA), HC2 hrHPV testing from the SurePath vial to date has not been able to obtain FDA approval, despite multiple premarket approval submissions, beginning in $2002 .{ }^{8}$ In a 2002 press release, the manufacturer stated: "We remain hopeful that resolution of the FDA's issues will not significantly alter our prior expectations for introduction in 2003." ${ }^{\text {8 }}$ Qiagen investigators have acknowledged that purification of DNA from SurePath specimens requires complex sample preparation due to the formaldehyde crosslinking of proteins and nucleic acids. ${ }^{9}$ Three additional hrHPV tests have now also gained FDA approval from either the PreservCyt vial or also from proprietary manufacturer's collection media, but none of these newer FDA-approved hrHPV tests have been approved using the SurePath vial. ${ }^{10-12}$

Recently, the authors encountered a patient diagnosed with invasive cervical cancer with two prior significantly abnormal Pap tests and two negative hrHPV LDT cotest results. Since virtually all cervical cancers are now thought to be due to persistent carcinogenic hrHPV infections, ${ }^{13,14}$ this case was investigated to better understand the possible causes of negative hrHPV LDT in screened patients developing cervical cancer.

\section{Case report}

The patient was a young woman in her 30 s, a gravida 3 , para 3 cigarette smoker with a long history of abnormal Pap test results and inconsistent follow-up due to medical appointment cancellations which the patient attributed to intermittent lack of insurance coverage. Forty-two months before her diagnosis of cervical cancer, the patient had a SurePath Pap test interpreted as "atypical squamous cells, cannot rule out a high grade squamous intraepithelial lesion" (Figure 1). Because the patient's gynecologist had ordered routine cytology and HPV cotesting in a woman 30 years and older, the residual SurePath vial fluid was sent to a regional laboratory facility of a large national commercial laboratory. The hrHPV test result was reported as "not detected." In that report, an additional comment stated that "patients without hrHPV rarely have cervical cancer." There was no comment concerning the performance characteristics of this LTD. A cervical biopsy obtained 4 months later reported koilocytosis and an endocervical curetting as benign. A second SurePath Pap test obtained 19 months later was reported as "high-grade squamous intraepithelial lesion." The patient failed to return for scheduled colposcopic evaluation. Eighteen months later, the patient presented with irregular painful periods that were getting worse. A third SurePath Pap test was obtained and reported as "high-grade squamous intraepithelial lesion" (Figure 2). The patient's gynecologist had again ordered routine cytology and hrHPV cotesting in a woman 30 years or older, and therefore the residual SurePath vial fluid was again sent to the regional laboratory that had previously performed hrHPV testing. The hrHPV
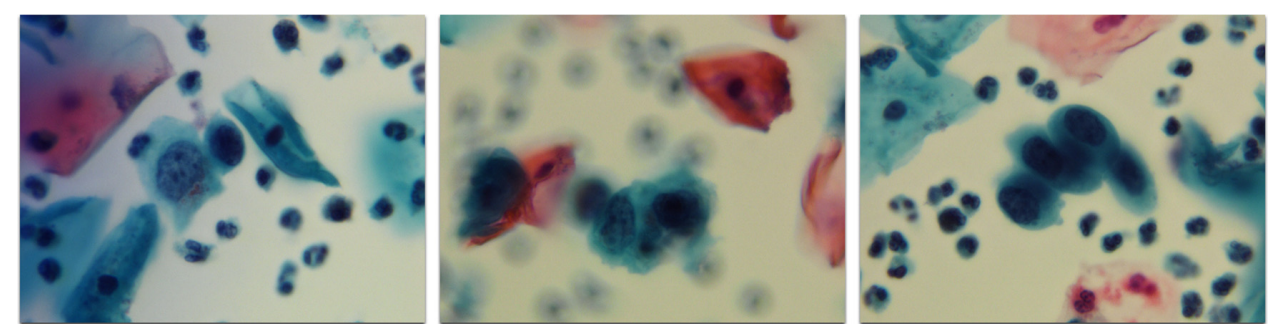

Figure I Abnormal SurePath Pap test cells interpreted as "atypical squamous cells, cannot rule out a high-grade squamous intraepithelial lesion" (original magnification 400x); residual SurePath vial fluid tested negative using the Hybrid Capture 2 test for high-risk human papillomavirus.

Note: Forty-two months later the patient was diagnosed with stage IBI cervical squamous cell carcinoma. 

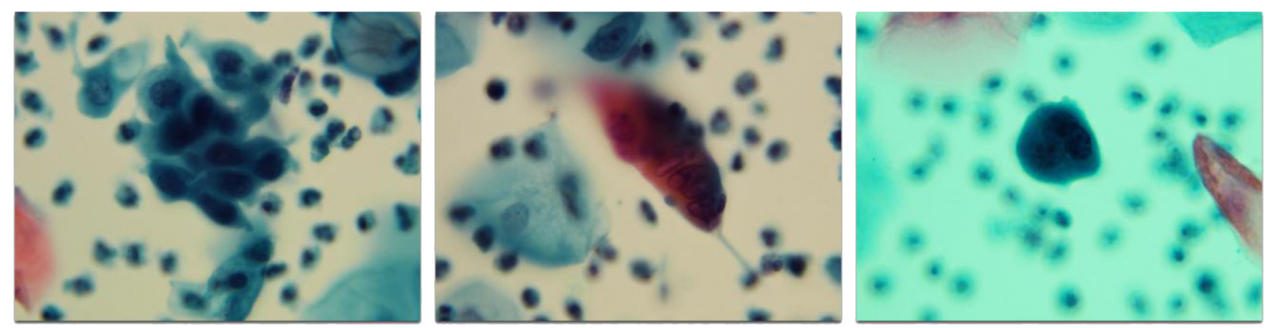

Figure 2 Abnormal SurePath Pap test cells interpreted as "high-grade squamous intraepithelial lesion" (original magnification 400x); residual SurePath vial fluid tested negative using the Hybrid Capture 2 test for high risk human papillomavirus.

Note: One month later the patient was diagnosed with stage IBI cervical squamous cell carcinoma.

test, which utilized hybrid capture with signal amplification, was - as before - reported as "not detected." In this report, however, an additional comment stated that "the analytical performance characteristics of this assay, when used to test SurePath or vaginal specimens, have been determined by (the laboratory)." The patient's SurePath Pap test slides were reviewed and photographed for documentation.

A cold knife conization was performed 1 month later and the presence of a poorly differentiated squamous cell carcinoma (SCC) measuring $1 \times 1 \times 0.5 \mathrm{~cm}$ and extending to multiple biopsy margins was documented. One month later at an outside cancer referral center, the patient underwent a radical hysterectomy, bilateral pelvic lymph node dissection, bilateral salpingectomy, and left oophorectomy.
Final pathologic diagnosis was of a cervical SCC $(1.5 \mathrm{~cm}$ maximum tumor dimension) invading the upper third of the cervix with no lymphovascular invasion identified, and negative lymph nodes - stage 1B1 (Figure 3). No further therapy was recommended. Twenty-six months later, at last follow-up, the patient was reported as alive and well with no evidence of disease.

Paraffin sections of SCC samples from the patient's cold knife conization specimen were used for hrHPV testing by polymerase chain reaction methods. ${ }^{15} \mathrm{HPV}$ in tumor sections was initially tested for using M09/M11 PCR primers, which amplify an approximately 450 base pair conserved region of the L1 gene of HPV. HPV type-specific PCR was also performed by PCR amplification of portions of E6 and E7

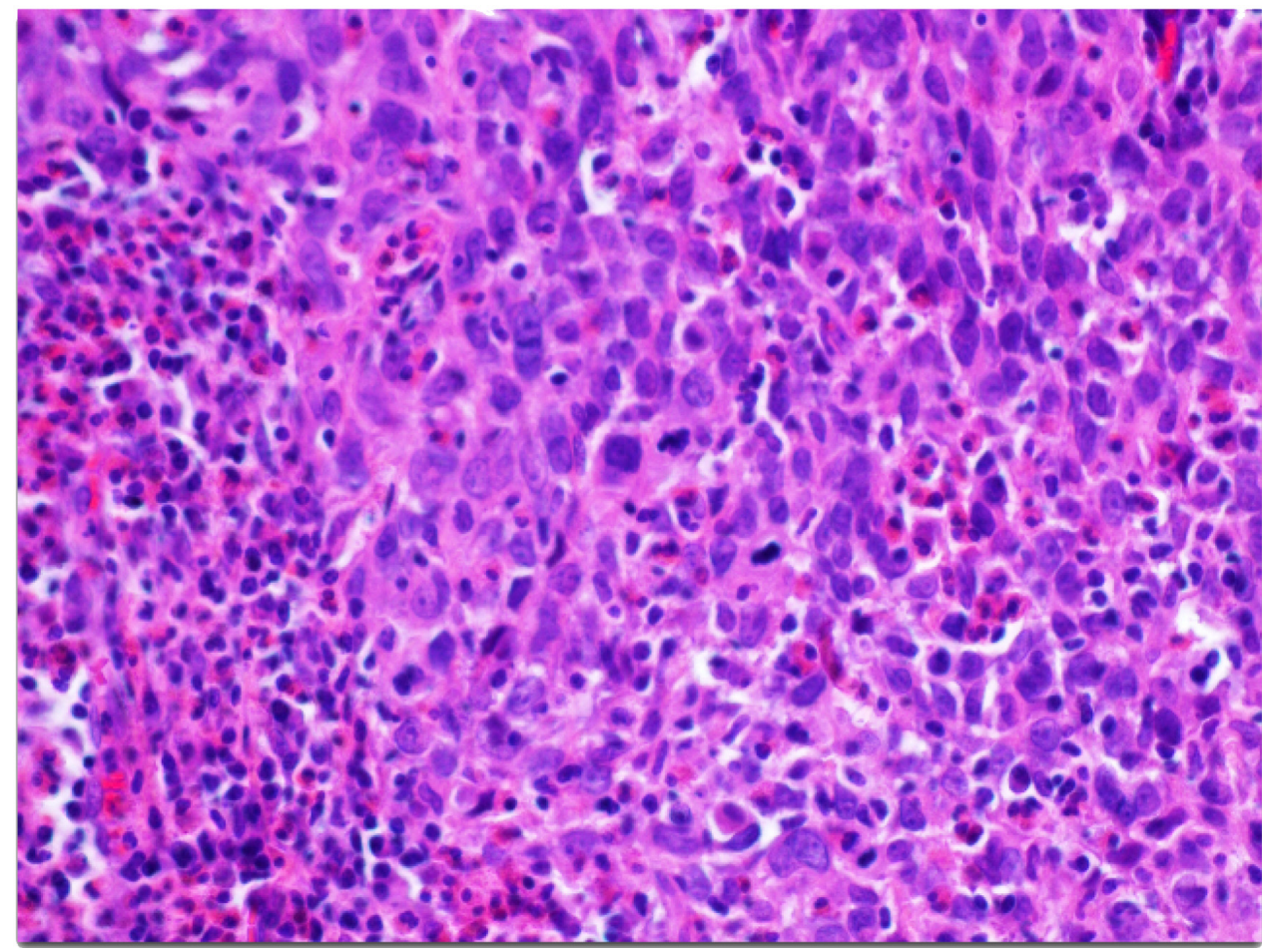

Figure 3 Invasive poorly differentiated cervical squamous carcinoma (original magnification 200x); diagnosed after two negative Hybrid Capture 2 human papillomavirus tests from SurePath vial fluid.

Note: Human papillomavirus 16 DNA was detected in tumor tissue by polymerase chain reaction. 
followed by automated DNA sequencing of the amplified products. Using these methods, presence of HPV 16 typespecific E6 was documented along with L1 deletion. Thus, the hrHPV tests from the SurePath vials were true false negative results. Fortunately, in the case of this patient, the false negative results did not affect her course or management.

\section{Discussion}

Confirmation of the presence of HPV 16 DNA by PCR in this patient's invasive cervical SCC is consistent with the current understanding that persistent infections with a group of approximately a dozen carcinogenic HPV genotypes cause virtually all cases of cervical cancer worldwide. However, negative HC2 hrHPV test results from residual SurePath vial fluid 42 months and 1 month before tumor diagnosis were unexpected. Since both Pap tests contained highly abnormal cells (atypical squamous cells, cannot rule out a high-grade squamous intraepithelial lesion and high-grade squamous intraepithelial lesion), the discrepancy cannot be attributed to a failure to sample lesional cells. In fact, it has been argued that one advantage of $\mathrm{HC} 2$ cotesting is that $\mathrm{HC} 2$ may detect hrHPV DNA in patients with occult invasive cervical cancer, even when lesional cells are not sampled. ${ }^{16}$

In the largest study of $\mathrm{HC} 2$ tests collected in FDAapproved specimen transport medium, positive hrHPV HC2 results were reported in 185 of 198 (93.4\%) samples collected from patients with simultaneous histopathologic diagnoses of invasive cervical cancer. ${ }^{17}$ In the same study, similar positive hrHPV HC2 test results were reported in 246 of 264 (93.2\%) specimen transport medium tubes collected from patients with simultaneous histopathologic diagnoses of grade 3 cervical intraepithelial neoplasia. ${ }^{17}$ In contrast, the very limited data from the most widely cited US laboratory self-validation study of HPV testing from the SurePath vial showed positive hrHPV HC2 results for patients with cancer in only $33 \%$ (one of three tests) or $50 \%$ (one of two patients). Also in contrast to the above cited data, the authors puzzlingly asserted that false negative hrHPV screening test results in patients with invasive cervical cancer are "not surprising."7

HC2 uses a positive cut point of 1.0 relative light units per positive control, a cut point which corresponds to greater than or equal to $5000 \mathrm{HPV}$ DNA copies per test well, based on a receiver operating characteristic curve analysis versus cervical intraepithelial neoplasia grade $2+$, to minimize the detection of lower viral load HPV infections that are mostly benign. ${ }^{18-20}$ Nevertheless, a subset of invasive cervical cancers associated with low viral load have been described, ${ }^{21}$ and low viral loads in patients with developing invasive cervical cancer may fall below the detection cut point of FDA-approved hrHPV tests such as HC2. ${ }^{17,22}$ In one of the authors' own laboratories (RMA), three of 31 (10\%) patients diagnosed with invasive cervical SCC and tested within the prior 12 months for hrHPV by $\mathrm{HC} 2$ from FDA-approved PreservCyt vial fluid had negative $\mathrm{HC} 2$ results. ${ }^{23}$ All three patients had HPV 18 detected by PCR in SCC sampled in paraffin sections, and two also had detectible HPV $16 .^{23}$

HPV testing from the non-FDA-approved SurePath vial is thought to be more challenging, primarily due to the formaldehyde crosslinking of proteins and nucleic acids. ${ }^{9,24}$ Although recovery of DNA and ribonucleic acid is largely unaffected by long-term storage in PreservCyt, ${ }^{25,26}$ storage in SurePath preservative fluid (Becton Dickinson) has been shown to affect the recovery of both DNA and ribonucleic acid. ${ }^{27,28}$ Upon exposure to SurePath media, recovery of both DNA and ribonucleic acid rapidly diminished. This reduction was most apparent in the $0-150$ hours range (ie, up to around 6 days). ${ }^{27}$ The websites of four large national laboratories that offer HC2 testing of referred SurePath samples all indicated that SurePath samples are stable at room temperature for $\mathrm{HC} 2$ testing for $\leq 1$ month compared to 90 days/3 months for the FDA-approved ThinPrep ${ }^{\circledR}$ vial (Hologic) (Table 1). Interestingly, none of the laboratories, when queried by telephone, could produce independent SurePath-HC2 stability data; instead, laboratories referred to the FDA-approved Becton Dickinson package insert which states that SurePath preservative fluid preserves cells (for cytologic testing) for up to 4 weeks at room temperature $\left(15^{\circ} \mathrm{C}-30^{\circ} \mathrm{C}\right) .{ }^{29}$ Even in the most widely cited "validation" study mentioned previously, the authors referred to the digene package insert for specimen stability parameters. ${ }^{7}$ ACCURUN ${ }^{\circledR} 372$ series 400; (SeraCare Life Sciences, Inc, Milford, MA), ${ }^{31}$ the HPV proficiency testing vendor for the College of American Pathologists has

Table I Testing times allowed for of samples collected for Hybrid Capture 2 human papillomavirus testing as indicated on national laboratory websites

\begin{tabular}{llll}
\hline Laboratory & $\begin{array}{l}\text { Digene }^{\circledR} \\
\text { STM }\end{array}$ & ThinPrep $^{\circledR}$ & SurePath $^{\text {TM }}$ \\
\cline { 2 - 3 } & \multicolumn{2}{l}{ Room temperature/refrigerated } \\
\hline A & I4 days/ & 3 months/ & I month/ \\
& 21 days & 3 months & 6 months \\
B & 21 days/ & 3 months/ & 21 days/ \\
& unstable & 3 months & unstable \\
C & Not listed & 90 days/ & 28 days/ \\
& & 90 days & 28 days \\
D & I4 days/ & 90 days/ & 30 days/ \\
& 2I days & 90 days & 30 days \\
\hline
\end{tabular}

Abbreviation: STM, specimen transport medium. 
reported that HPV 16-positive control samples shipped in SurePath fluid degraded so rapidly that detectible HPV DNA was lost after 1 day. ${ }^{30}$ The vendor concluded that only use of a two tube methodology, separating the HPV 16 sample from the SurePath sample until the time of testing, could be used for laboratory HPV proficiency testing. ${ }^{31,32}$

There is at present no standardized SurePath HPV protocol that all laboratories use and no literature with sufficient detail to represent an agreed upon standard. .,7,33-36 $^{-3}$ Furthermore, the manufacturer cannot under current regulations recommend standardized procedures for non-FDAapproved hrHPV testing. As a result of continued ongoing widespread off-label HPV LDT use and related patient safety concerns, on June 8, 2012 the manufacturer of SurePath released a technical bulletin which stated:

"The Becton Dickinson SurePath sample medium has not been approved by the FDA for use with the HC2 test and use $[\ldots]$ may under certain conditions provide false negative results. False negative results could lead to inappropriate patient management and potentially compromise patient safety."

\section{Conclusion}

The authors echo the cautions of the new US screening guidelines that emphasize that extended screening intervals following negative hrHPV test results be based on HPV tests with performance characteristics similar to HPV tests used in the supporting evidence. Such supporting evidence is so far lacking for the hrHPV LDTs described here. Given those new cervical screening guidelines and manufacturer communications that caution against non-FDA-approved LDT hrHPV testing from the SurePath vial, it is reasonable to view continued widespread use of this nonstandardized off-label testing as a patient safety issue. With new, extended 5 -year screening intervals proposed for many women, an increasing number of women will be screened every 5 years. An avoidable increase in false negative hrHPV results in women with both precancer and early invasive cervical cancer will place patients at unnecessary risk. The use of screening methods that have not been validated should be strongly discouraged. ${ }^{37,38}$ With four FDA-approved alternatives, it is difficult to justify the use of anything but rigorously clinically validated specimens. The College of American Pathologists should discontinue offering its current form of laboratory proficiency testing for HPV testing out of the SurePath vial, as it could mislead participants to believe that their methodology is currently safe and acceptable. For laboratories that use SurePath for cytology, co-collection of a second sample for hrHPV testing in an FDA-approved collection medium provides a safe and effective alternative.

\section{Disclosure}

The authors report no conflicts of interest in this work.

\section{References}

1. Wright TC Jr, Cox JT, Massad LS, et al. 2001 Consensus Guidelines for the management of women with cervical cytological abnormalities. JAMA. 2002;287(16):2120-2129.

2. US Food and Drug Administration. FDA news: FDA approves expanded use of HPV test. FDA News. March 31, 2003. Available from: http:// www.fda.gov/ohrms/dockets/dockets/07p0210/07p-0210-ccp0001-01FDA-News-vol3.pdf. Accessed August 9, 2012.

3. Saslow D, Solomon D, Lawson HW, et al. American Cancer Society, American Society for Colposcopy and Cervical Pathology, and American Society for Clinical Pathology screening guidelines for the prevention and early detection of cervical cancer. Am J Clin Pathol. 2012;137(4):516-542.

4. Vance GH. College of American Pathologists proposal for the oversight of laboratory-developed tests. Arch Pathol Lab Med. 2011; 135(11):1432-1435.

5. Clavel C, Masure M, Putaud I, et al. Hybrid Capture II, a new sensitive test for human papillomavirus detection. Comparison with Hybrid Capture I and PCR results in cervical lesions. J Clin Pathol. 1998;51(10):737-740.

6. Siddiqui MT, Cohen C, Nassar A. Detecting high-grade cervical disease on ASC-H cytology: role of BD ProEx C and digene Hybrid Capture II HPV DNA testing. Am J Clin Pathol. 2008;130(5):765-770.

7. Ko V, Tambouret RH, Kuebler DL, Black-Schaffer WS, Wilbur DC. Human papillomavirus testing using Hybrid Capture II with SurePath collection: initial evaluation and longitudinal data provide clinical validation for this method. Cancer. 2006;108(6):468-474.

8. TriPath Imaging. Comments on the FDA review of Digene's PMA application [press release]. Burlington, NC: TriPath Imaging; July 10, 2002.

9. Kupfer C, Lindebaum K, Giles J, Chendvankar R, Lee Y, SprengerHaussels M. QIAsymphony AXpH sample preparation for automated conversion of liquid-based cytology specimens for use in the digene HC2 high-risk HPV DNA test. Paper presented at: EUROGIN 2011 Congress; May 8-11, 2011; Lisbon, Portugal.

10. Belinson JL, Wu R, Belinson SE, et al. A population-based clinical trial comparing endocervical high-risk HPV testing using Hybrid Capture 2 and Cervista from the SHENCAST II study. Am J Clin Pathol. 2011;135(5):790-795.

11. Stoler MH, Wright TC Jr, Sharma A, et al. The interplay of age stratification and HPV testing on the predictive value of ASC-US cytology. Am J Clin Pathol. 2012;137(2):295-303.

12. Ratnam S, Coutlee F, Fontaine D, et al. Aptima HPV E6/E7 mRNA test is as sensitive as Hybrid Capture 2 assay but more specific at detecting cervical precancer and cancer. J Clin Microbiol. 2011;49(2):557-564.

13. Bosch FX, Lorincz A, Munoz N, Meijer CJ, Shah KV. The causal relation between human papillomavirus and cervical cancer. J Clin Pathol. 2002; 55(4):244-265.

14. Bouvard V, Baan R, Straif K, et al. A review of human carcinogens part B: biological agents. Lancet Oncol. 2009;10(4):321-322.

15. Ferris RL, Martinez I, Sirianni N, et al. Human papillomavirus-16 associated squamous cell carcinoma of the head and neck (SCCHN): a natural disease model provides insights into viral carcinogenesis. Eur J Cancer. 2005;41(5):807-815.

16. Kinney W, Fetterman B, Cox JT, Lorey T, Flanagan T, Castle PE. Characteristics of 44 cervical cancers diagnosed following Pap-negative, high risk HPV-positive screening in routine clinical practice. Gynecol Oncol. 2011;121(2):309-313. 
17. Kang WD, Kim CH, Co MK, et al. Comparison of Hybrid Capture II assay with the human papillomavirus DNA chip test for the detection of high-grade cervical lesions. Int $J$ Gynecol Cancer. 2009;19(5):924-928.

18. Sherman ME, Schiffman M, Cox JT. Effects of age and human papilloma viral load on colposcopy triage: data from the randomized Atypical Squamous Cells of Undetermined Significance/Low-Grade Squamous Intraepithelial Lesion Triage Study (ALTS). J Natl Cancer Inst. 2002;94(2):102-107.

19. Kinney W, Stoler MH, Castle PE. Special commentary: patient safety and the next generation of HPV tests. Am J Clin Pathol. 2010; 135(2):193-199.

20. Ronco G, Giorgi-Rossi P, Carozzi F, et al. Results at recruitment from a randomized controlled trial comparing human papillomavirus testing alone with conventional cytology as the primary cervical cancer screening test. J Natl Cancer Inst. 2008;100(7):492-501.

21. Boulet GA, Benoy IH, Depuydt CE, et al. Human papillomavirus 16 load and E2/E6 ratio in HPV16-positive women: biomarkers for cervical intraepithelial neoplasia $\geq 2$ in a liquid-based cytology setting. Cancer Epidemiol Biomarkers Prev. 2009;18(11):2992-2999.

22. Katki HA, Kinney WK, Fetterman B, et al. Cervical cancer risk for women undergoing concurrent testing for human papillomavirus and cervical cytology: a population-based study in routine clinical practice. Lancet Oncol. 2011;12(7):663-672.

23. Li Z, Austin RM, Guo M, Zhao C. Screening test results associated with cancer diagnoses in 287 women with cervical squamous cell carcinoma. Arch Pathol Lab Med. August 20, 2012; [Epub ahead of print.]

24. Moelans CB, Oostenrijk D, Moons MJ, van Diest PJ. Formaldehyde substitute fixatives: effects on nucleic acid preservation. J Clin Pathol. 2011; 64(11):960-967.

25. Cuschieri KS, Beattie G, Hassan S, Robertson K, Cubie H. Assessment of human papillomavirus mRNA detection over time in cervical specimens collected in liquid based cytology medium. JVirol Methods. 2005;124(1-2):211-215.

26. Lin WM, Ashfaq R, Michalopoulos EA, Maitra A, GazdarAF, Muller CY. Molecular Papanicolaou tests in the twenty-first century: molecular analyses with fluid-based Papanicolaou technology. Am J Obstet Gynecol. 2000;183(1):39-45.

27. Powell N, Smith K, Fiander A. Recovery of human papillomavirus nucleic acids from liquid-based cytology media. J Virol Methods. 2006;137(1):58-62.
28. Arbyn M, Andersson K, Bergeron C, Bogers JP, von Knebel-Doebertitz M, Dillner J. Cervical cytology biobanks as a resource for molecular epidemiology. Methods in Mol Biol. 2011;675:279-298.

29. SurePath ${ }^{\circledR}$ collection [package insert]. Franklin Lakes, NJ: Becton, Dickinson and Company; 2011.

30. Anekella B, Dryga S, Moskowitz K, et al. Stability of integrated HPV16 DNA in various sample transport media. J Mol Diagn. 2007;9:679-680.

31. SeraCare Life Sciences, Inc. ACCURUN ${ }^{\circledR} 372$ series 400 HPV DNA positive control. Available from: http://www.seracarecatalog.com/ Default.aspx?tabid=219\&txtSearch=A3\&List=1\&SortField=Produ ctName\%2CProductName\&ProductID=121\#LiveContent[ACC-P]. Accessed July 16, 2012.

32. Moriarty AT, Bentz JS, Winkler B, et al. Proficiency testing of high risk human papillomavirus DNA tests: the first 3 years of experience of the College of Pathologists CHPV surveys. Arch Pathol Lab Med. Forthcoming 2012.

33. Davis-Devine S, Day SJ, Freund GG. Test performance comparison of inform HPV and Hybrid Capture 2 high-risk DNA test using the SurePath liquid-based Pap test as the collection method. Am J Clin Pathol. 2005;124(1):24-30.

34. Siddiqi A, Spataro M, McIntire H, et al. Hybrid capture 2 human papillomavirus DNA testing for women with atypical squamous cells of undetermined significance Papanicolaou results in SurePath and ThinPrep specimens. Cancer. 2009;117(5):318-325.

35. Zhao FH, Hu SY, Bian JJ, et al. Comparison of ThinPrep and SurePath liquid-based cytology and subsequent human papillomavirus DNA testing in China. Cancer Cytopathol. 2011;119(6):387-394.

36. Kelly RS, Patnick J, Kitchener HC, Moss SM. HPV testing as a triage for borderline or mild dyskaryosis on cervical cytology: results from the Sentinel Sites study. Br J Cancer. 2011;105(7):983-988.

37. Stoler MH, Castle PE, Solomon D, Schiffman M. The expanded use of HPV testing in gynecologic practice per ASCCP-guided management requires the use of well-validated assays. Am J Clin Pathol. 2007; 127(3):335-337.

38. Naryshkin S, Austin RM. Limitations of widely used high risk HPV DNA testing in patients with invasive cervical cancer. Paper presented at: EUROGIN 2011 Congress; May 8-11, 2011; Lisbon, Portugal.
Drug, Healthcare and Patient Safety

\section{Publish your work in this journal}

Drug, Healthcare and Patient Safety is an international, peer-reviewed open-access journal exploring patient safety issues in the healthcare continuum from diagnostic and screening interventions through to treatment, drug therapy and surgery. The journal is characterized by the rapid reporting of reviews, original research, clinical, epidemiological and

\section{Dovepress}

post-marketing surveillance studies, risk management, health literacy and educational programs across all areas of healthcare delivery. The manuscript management system is completely online and includes a very quick and fair peer-review system. Visit http://www.dovepress.com/ testimonials.php to read real quotes from published authors. 